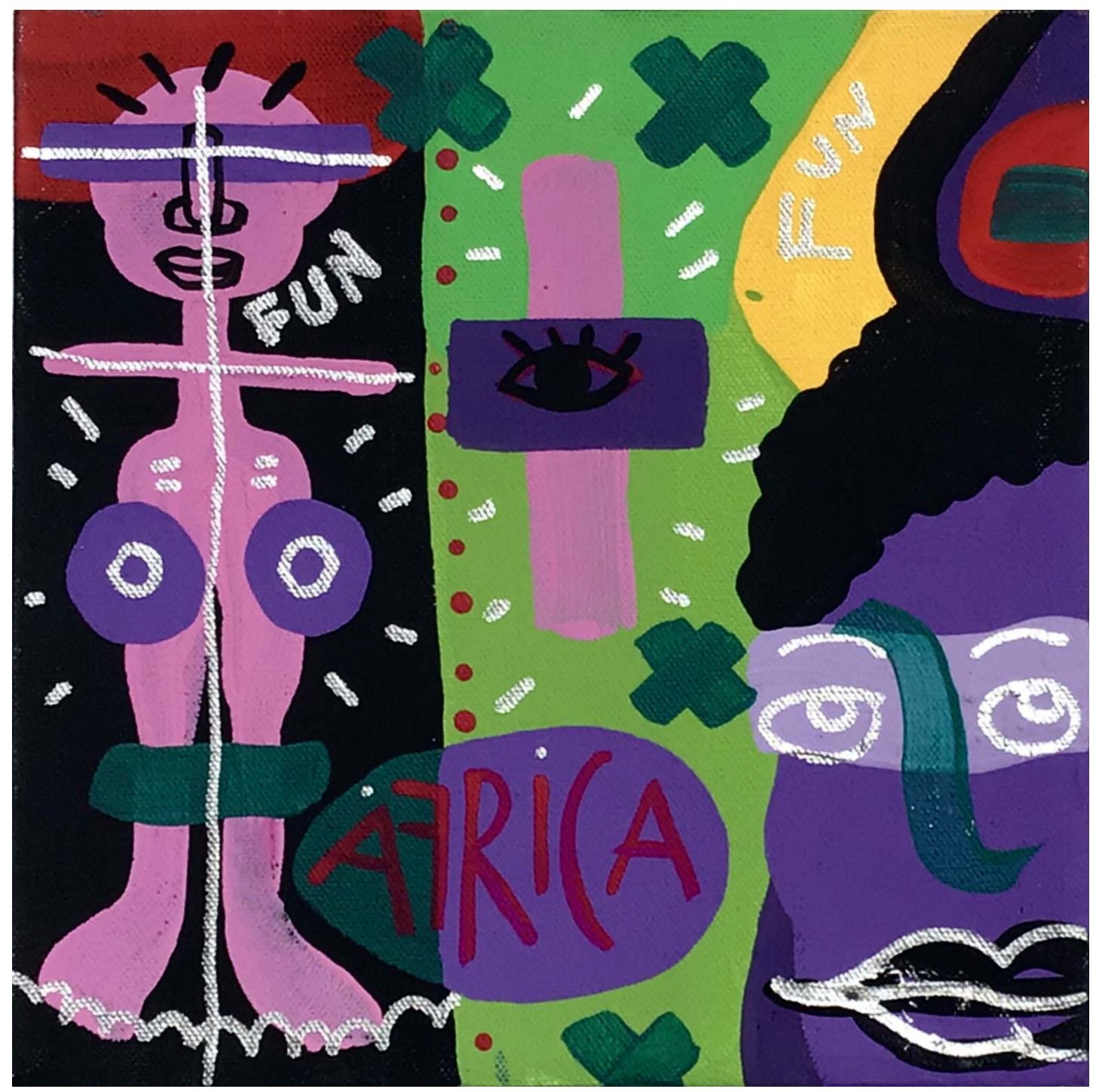

Artista invitado

Fabio Andrés Arboleda Mendoza

Afrika

De la serie neWeed

Acrílico sobre lienzo

$20 \times 20 \mathrm{~cm}$

2020

Medellín 


\title{
Performatividad del cuerpo precario de los migrantes venezolanos. Defensa contra una amenaza producida por el estado de inseguridad en Colombia*
}

\author{
Ingrid Tatiana Abril Peña (Colombia)**
}

\section{Resumen}

Este artículo de reflexión aborda el estado de inseguridad desplegado por el Estado neoliberal en Colombia, a partir de una experiencia de conflicto social contemporáneo enmarcado en la jornada de protestas que estallaron en Bogotá en noviembre de 2019 y su relación con la crisis migratoria de Venezuela. El corpus de este análisis está conformado por publicaciones — videos, comentarios, fotos y noticias- que circularon en el grupo público de Facebook Arriendos Bogotá durante los días 21 y 22 de noviembre, cuyo contenido referencia a las protestas o desmanes presentados y que señala como responsables a los migrantes venezolanos. De esta manera, la finalidad de este artículo es problematizar estos actos comunicativos para abordarlos como actos performativos de poder político y económico que producen y reproducen un régimen de precarización de la vida. El análisis se hará en torno a los planteamientos de Isabell Lorey y Judith Butler para comprender cómo se construye de manera performativa - a través de registros visuales- el cuerpo y el rostro de un precario, siendo este una reproducción de una amenaza y desestabilización de un otro que se configura como amenazado desde la perspectiva del orden y la seguridad nacional, para al final mostrarlo como un enemigo que debe eliminarse o por ser ese exceso no gobernable.

\section{Palabras clave}

Migración; Subjetividades; Comportamiento Político; Cuerpos Precarios; Performatividad; Estado de Inseguridad.

Fecha de recepción: noviembre de 2020

- Fecha de aprobación: mayo de 2021

\footnotetext{
* Este artículo de reflexión se produce en el marco de la investigación Configuración de masculinidades en los filmes: El río de las tumbas (1967); El día de las Mercedes (1985); Golpe de Estadio (1998) y Monos (2019), para optar por el título de magíster en Estudios Sociales, Universidad Pedagógica Nacional.

** Abogada. Magíster en Estudios Sociales. Docente adscrita a la Secretaría de Educación de Floridablanca, Santander. Correo electrónico: intabril@gmail.com - Orcid: 0000-0002-9186-2284
} 


\title{
Cómo citar este artículo
}

Abril Peña, Ingrid Tatiana. (2021). Performatividad del cuerpo precario de los migrantes venezolanos. Defensa contra una amenaza producida por el estado de inseguridad en Colombia. Estudios Políticos (Universidad de Antioquia), 62, pp. 106-125. https://doi.org/10.17533/udea.espo.n62a05

\section{Performativity of Precarious Bodies of the Venezuelan Migrants. Defense against a Threat Produced by Insecurity in Colombia}

\begin{abstract}
This article reflects on the state of insecurity displayed by the neoliberal State in Colombia, based on an experience of contemporary social conflict framed in the day of protests that broke out in Bogotá, in November 2019, and its relationship with the migratory crisis of Venezuela. The corpus of this analysis is made up of publications (videos, comments, photos and news) that circulated on the Facebook public group Arriendos Bogotá during November 21 and 22, the content of which refers to the protests or excesses presented, and which indicates Venezuelan migrants as responsible. In this way, the purpose of this article is to problematize these communicative acts to approach them as performative acts of political and economic power that produce and reproduce a regime of precariousness of life. The analysis will be made in line with the approaches of Isabell Lorey and Judith Butler to understand how the body and face of precarious people are constructed in a performative way through visual registers, being this a reproduction of a threat and destabilization of an other that is configured as threatened, from the perspective of order and national security, in order to show these people as enemies that must be eliminated because that excess is not governable.
\end{abstract}

\section{Keywords}

Migration; Subjectivities; Political Behavior; Precarious Bodies; Performativity; State of Insecurity. 
Los vándalos de esa noche son como los fantasmas: todos hemos oído hablar de ellos, algunos creyeron verlos y a todos nos asustaron (Caballero, 2020, agosto 24).

\section{Introducción}

El 21 de noviembre del 2019 fue un día histórico para el Colombia: miles de personas marcharon por el elevado aumento en los impuestos, la amenaza de la eliminación-modificación en la seguridad pensional, la privatización de las empresas del Estado, el incremento de los servicios públicos, la propuesta de reducción del salario mínimo para los jóvenes y el sistemático asesinato de líderes sociales e indígenas (Caballero, 2020, agosto 24).

En el transcurso de las manifestaciones, la imagen de los migrantes venezolanos no había tenido visibilidad, sino hasta que se generó una participación masiva en la web.

Desde el auge de Internet y su uso masivo se incrementó la interacción de comunidades por medio de las denominadas redes sociales. Estas se

[108] constituyeron como un espacio de organización y participación de los usuarios. Los grupos de Facebook, por ejemplo, tienen diferentes objetos que pueden ir desde la prestación de servicios sociales, venta de bienesservicios, un punto de encuentro de los simpatizantes de alguna idea, hasta un lugar para conocer la oferta de arriendos de alguna ciudad. Cada día aumenta el número de personas conectadas a la red.

Durante todo el día y los siguientes que les acontecieron a las marchas hubo una hipercirculación en redes sociales de videos en los que aparecían grupos de personas que saqueaban casas, conjuntos y supermercados (Caballero, 2020, agosto 24; Burbano, 22 de noviembre de 2019). Se generó un pánico colectivo que temía por el daño a la propiedad privada y la seguridad de los ciudadanos. Esta situación anunciada por la web conllevó a que vecinos y habitantes de diversos sectores, principalmente populares, se armaran con palos, cuchillos y hasta machetes para defenderse ante el Ilamado viral: el de la violencia y la intrusión de la propiedad de las familias colombianas (Caballero, 2020, agosto 24). El 22 de noviembre, el Gobierno colombiano, frente a los supuestos saqueos y el presunto riesgo que corría la seguridad nacional, decretó toque de queda a partir de las 9:00 pm. En el caso de la ciudad de Bogotá, esta fue militarizada. 
Esta situación produjo un otro-amenaza al que se le acusaba de generar la inseguridad de los ciudadanos frente a su propiedad. El miedo y la zozobra se coprodujeron con la exposición a la peligrosidad, la cual comenzó a adquirir el cuerpo y rostro de los ciudadanos venezolanos. De un momento a otro, algunos usuarios del grupo público de Facebook Arriendos Bogotá (s. f.) empezaron a circular la idea de que estas personas eran las responsables de todos los desmanes, en particular, de los robos y saqueos a conjuntos cerrados y locales comerciales.

Un cuerpo reproducido como precario es a quien el poder discursivo reitera que debe ser objeto de violencia justificada, en este sentido, opera la performatividad, uno de los aportes de la filósofa Judith Butler (2002), que la define como «práctica referencial y reiterativa por medio de la cual el discurso produce aquello que nombra» (p. 18). No es un acto único y singular desplegado de la voluntad de un individuo que da vida a lo que Ilama, sino que es el poder reiterativo del discurso que precede, obliga y excede a quien efectúa la acción y que al repetirse como acto en el presente se invisibiliza. Es una cadena de citas en el tiempo con la cual el Ilamado de esta conforma su carácter y fuerza performativa, histórica pero encubierta. Esta noción la desarrolla Butler a partir de los actos del habla del filósofo del lenguaje John Austin, que considera el uso de la palabra como un acto realizado, es decir, cada vez que se habla se están haciendo cosas: negar, declarar, mentir, advertir, amenazar. Todas ellas traen consigo un acto (Butler, 2002).

Este artículo es una reflexión de carácter exploratorio que se genera a partir de un ejercicio de etnografía visual a partir de la perspectiva de Christine Hine (2004), que entiende Internet como cultura y artefacto cultural, «reconociendo que no es la tecnología en sí misma la que es agente de cambio, sino que son los usos y la construcción de sentido alrededor de ella» (p. 9). Dicho de otro modo, este nuevo enfoque metodológico es una posibilidad para comprender procesos y relaciones socioafectivas que se despliegan en el ciberespacio; asimismo, para entender cómo estas logran desplazar los marcos de interpretación de un acontecimiento. Se seleccionó el grupo público de Facebook Arriendos Bogotá porque, aunque el objeto de este espacio es buscar u ofrecer un lugar para vivir - habitación, casa o apartamento-, durante los desmanes se convirtió en arena de disputa política. 
Dada la imposibilidad de contener la circulación de información debido a la velocidad con la que se consume y elimina en las redes, se recolectaron capturas de pantalla de las publicaciones realizadas por algunos usuarios a los que se les dejará únicamente la primera letra del nombre por motivos de seguridad. En ninguno de los comentarios hubo participación ni comunicación con estas personas porque el objetivo no era intervenir en aquellas relaciones de forma directa, sino observar cómo opera el discurso de manera performativa para producir un otro como amenaza. Por esta razón, el propósito del artículo es indagar en la relación entre la producción del estado de inseguridad y la configuración del cuerpo precario de los ciudadanos venezolanos, a través de la reproducción de los comentarios dados en el grupo público de Facebook Arriendos Bogotá durante los hechos de protesta de noviembre de 2019 en la ciudad de Bogotá.

Respecto a la población venezolana, el fenómeno de migración hacia otros países se ha incrementado a partir de 2015 (Taraciuk, 2018, septiembre 5). Ya que Colombia es un país fronterizo, se ha convertido en uno de los más recurrentes destinos de migrantes venezolanos en Latinoamérica. Sin embargo, en 2020 la tasa disminuyó 2,35\% con respecto a los 1,77 millones de migrantes que Ilegaron a Colombia en 2019. A partir de la emergencia sanitaria en Colombia, producto de la pandemia de la Covid-19, miles de venezolanos han decidido de manera voluntaria regresar a su país de origen (Migración Colombia, 2021, enero 29). La migración forzada es producto de la crisis socioeconómica que enfrenta el país, interpretada y estudiada desde diferentes enfoques y disciplinas, a la cual se le han atribuido múltiples causas (Gandini, Ascenso y Prieto, 2019).

\section{Condición precaria, precariedad y precarización como gubernamentalidad}

Para construir un cuerpo precarizado, Isabelle Lorey (2016) establece tres dimensiones de lo precario: la condición precaria, la precariedad y la precarización como gubernamentalidad.

La precarización es la forma de control político y económico de la actualidad, no es una condición transitoria de marginalidad visualizada en la periferia de las grandes ciudades, donde se encuentran los barrios más pobres, sino que es un régimen basado en el constante estado de inseguridad que se genera de manera permanente para que todos los gobernados sientan 
la necesidad de inmunización: "como ideal político máximo, un ideal que sirve para acumular dentro del Estado y de las instituciones empresariales a la par que produce un nuevo tipo de sujeto» (Lorey, 2016, p. 14). Este nuevo sujeto se regula a sí mismo conforme a las nuevas políticas sociales, así se garantiza el éxito del nuevo principio organizador. Como estado general y permanente de las cosas, la incertidumbre y la contingencia son protagonistas en la producción de ese vacío que amenaza no solo la existencia en sí misma, sino también las condiciones de vida.

Para el Estado neoliberal en el que vivimos, el contrato social hobbesiano es inaplicable. Actualmente no es posible negociar paz y seguridad a cambio de restringir libertades individuales porque se opera a partir de una situación de inestabilidad para la población en general. Lo único que se garantiza es la inseguridad social con el fin de aumentar la exposición al peligro, de esta manera, se configuran los entornos de lo seguro a través de la producción, con unos márgenes de reconocimiento reiterados por medio de diferentes discursos en los que se avalan unas vidas a partir de la exclusión de otras. La amenaza de lo no seguro funciona por medio de la ampliación y reducción de la precarización; sin embargo, esta condición no es llevada al extremo, se mueve en un tire y afloje que sostiene la incertidumbre permanente (Lorey, 2016). El Sujeto en este marco se construye de manera individualizada y aislada: condiciones que lo absorben y producen nuevamente. A pesar de ello, lo único que los individuos tienen en común es la precariedad, no solo del trabajo y de las condiciones materiales, sino de la vida misma: tan rápida como el tiempo que alguien dura en un puesto laboral.

El estado de inseguridad en Colombia se reprodujo a través de redes sociales como Facebook, WhatsApp, Twitter, entre otras. Los siguientes son los comentarios de usuarios del grupo público de Facebook Arriendos Bogotá, son respuestas a los videos que circulaban en la web sobre los supuestos actos violentos y delitos atribuidos a los venezolanos. En la gráfica 1 aparecen las publicaciones de la usuaria D (comunicación personal, noviembre 22, 2019), una de las personas que se desborda en comentarios contra los migrantes venezolanos y los señalaba como responsables de la inseguridad del país, mientras empleaba el discurso acuñado por los medios de comunicación y el Gobierno sobre uno de los enemigos internos: el vandalismo-vándalo para referirse a una persona que comete actos delictivos en bienes públicos y privados, y en 
mayor medida cuando hay situaciones de protesta social (Rozo, 2019, octubre 11). Poco a poco, estos ataques comenzaron a subirse de tono y fueron parte de la cadena de citas que le ponía un rostro al peligro que se había producido.

Gráfica 1. Comentarios de la usuaria D.

\begin{tabular}{|c|c|}
\hline \multirow[t]{2}{*}{ O } & $\begin{array}{l}\text { Do he escuchado como dicen que los } \\
\text { colombianos son unos flojos que ellos trabajan más que } \\
\text { nosotros los colombianos es que son bien payasos después } \\
\text { que muchos estaban acostumbrados a que todo se los } \\
\text { regalaran creen que aca será lo mismo jajaja no vallan a } \\
\text { vender tinto y a limpiar zapatos así como lo hacen los } \\
\text { luchadores colombianos I }\end{array}$ \\
\hline & Me gusta Responder - 1 sem \\
\hline \multirow[t]{2}{*}{ 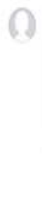 } & $\begin{array}{l}\text { D @Yisell bastante? Que pena mamita pero a } \\
\text { mi nunca me vieron por allá y mi familia tampoco jajajajajajaj } \\
\text { I'm sorry payasita pero ya venezuela no está en su "mejor } \\
\text { condición" fijate fijate fijate ahora están acá robando y } \\
\text { matando a quienes les ayudan a que no aguanten hambrel }\end{array}$ \\
\hline & Me gusta Responder - 1 sem \\
\hline \multirow[t]{2}{*}{0} & $\begin{array}{l}\text { D Yo si reconozco que hay venezolanos que } \\
\text { están trabajando honradamente pero hay más malos que } \\
\text { buenos se arda quien se arda le duela a quien le duela me } \\
\text { vale miles de hectáreas I }\end{array}$ \\
\hline & Me gusta Responder $1 \mathrm{sem}$ \\
\hline
\end{tabular}

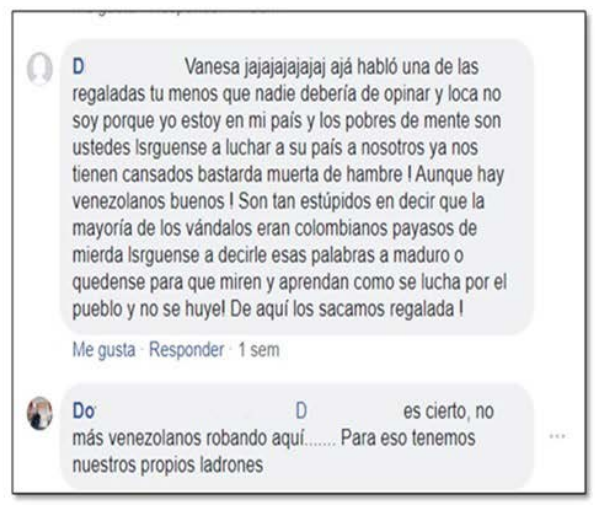

Fuente: captura de pantalla del grupo público de Facebook Arriendos Bogotá.

La usuaria $\mathrm{D}$, a pesar de reconocer que hay venezolanos «buenos», termina por afirmar que la mayoría son vándalos. En un artículo titulado jojo con la xenofobia!, publicado ocho días después de los acontecimientos de pánico colectivo, se pondera las acusaciones que podrían agravar la situación humanitaria de los migrantes. Los datos de la Fundación Ideas para la Paz afirman que $74,5 \%$ de los trinos de Twiter son comentarios despectivos hacia los venezolanos (Semana, 2019, noviembre 30).

Los dirigentes de Venezuela, Hugo Chávez y Nicolás Maduro, se han convertido en los enemigos públicos de los últimos gobiernos de derecha y ultraderecha en Colombia, quienes asocian a aquel país con el fantasma del comunismo. En consecuencia, se han apropiado discursos como el castrochavismo para referirse a la ideología de izquierda o independiente, la cual reproduce un peligro hacia las libertades de la democracia en Colombia. Este término fue acuñado por Álvaro Uribe Vélez y la bancada 
de su partido, Centro Democrático, para acusar al vecino país de nexos con las guerrillas tradicionales en el marco del conflicto colombiano. El sermón seremos como Venezuela si «X» $\mathrm{O}$ "y» candidato de la oposición, aunque al menos sea progresista, gana algún puesto de elección popular se ha convertido en discurso durante las campañas políticas. Estas reiteraciones en la política colombiana muestran la manera en que opera la performatividad para producir unos cuerpos como precarios y otros como valiosos.

La condición precaria y la precariedad están relacionadas, pero no son lo mismo. La existencia misma es una condición precaria de todos los cuerpos desde el nacimiento, ya que somos dependientes en lo concerniente al cuidado y protección para salvaguardarnos de los peligros. Esta interdependencia hace que la vida se encuentre en una condición precaria compartida, un aspecto común pero también de separación, en tanto todos se ven permanentemente amenazados, lo cual genera la posibilidad de dominio de un amenazado que excluye al que considera amenazador. La precariedad es una situación de interdependencia compartida por todos, somos precarios desde que nacemos; por ende, hay una condición general de vulnerabilidad en la cual «mi existencia no es solamente mía, sino que se puede encontrar fuera de mí, en esa serie de relaciones que preceden y exceden los límites de quién yo soy» (Butler, 2010, p. 72). Esto nos expone no solo frente a aquellos que conocemos, sino también con los que no conocemos y, por lo tanto, no podemos controlar (p. 30).

La precarización como gubernamentalidad es pensada a partir del planteamiento de la biopolítica de Michel Foucault (2014), el cual expresa que la protección-preservación de la vida y los cuerpos de los individuos son importantes para la conservación del Estado y la productividad capitalista. A partir de técnicas de autogobierno, el sujeto siente una participación consigo mismo, entendiéndose como propio, de sí y para sí, lo cual conlleva a considerar que puede incidir sobre su condición precaria y comienza a disolver el vínculo con los demás, de esta manera se fortalece el gobierno de los cuerpos y su individualización como posesión y autodisciplinamiento. En cambio, empoderamiento y subyugación son una paradoja: son condiciones simultáneas en las cuales el sujeto se autorregula. Según este dispositivo, la libertad se subjetiva en este sentido, aunque también implica una capacidad de acción, de agencia, lo que posibilita luchas y resistencias contra el poder dominante. 
La precariedad como gubernamentalidad no tiene una connotación negativa, tampoco es un peligro que pueda ser resuelto por el extinto Estado social, aquel encargado de brindar seguridad. La precariedad es normalización y tecnología de gobierno que opera a través de la inmunización biopolítica (Lorey, 2016), en cuanto asimila en el centro el peligro de la amenaza que es domesticada y neutralizada, esta no es desechada o eliminada por completo. En la misma línea, «los discursos de seguridad no pueden prescindir de los parámetros de la amenaza y la fuente de peligro, al objeto de legitimar su inmunización» (p. 55).

En el siglo xIx, la subjetivación a la gubernamentalidad estaba estrechamente relacionada e influenciada por las instituciones y técnicas de protección social, a la vez que brindaba mayor seguridad para aquellos que precarizaban a otros etiquetados como peligro y amenaza. La precarización es normalizada en el neoliberalismo, se convierte en un dispositivo de control (Lorey, 2016).

El peligro se encuentra al interior del corpus social infectado, es allí donde se producen las amenazas entendidas como el exceso de aquello que ya no es gobernable y, por lo tanto, debe ser desechado. Para Butler [114] (2002), esta es una matriz excluyente por medio de la cual se forman los sujetos a partir de los abyectos, término acuñado por la autora para referirse a aquellas zonas o espacios invivibles o inhabitables en las que se encuentra un cúmulo de la población que no goza del estatus de sujeto, que a su vez es necesaria para definir el campo de lo humano. Estos cuerpos ilegibles para la norma están marcados como restricción con poder productivo, que a su vez configuran el espacio de los cuerpos inteligibles, aceptables y reconocibles, a través de esos campos repudiados sobre los cuales se constituye lo humano como oposición, supresión y exclusión de lo inhumano, negándoles legitimidad simbólica, inteligibilidad cultural o la posibilidad de protección.

La usuaria M (comunicación personal, noviembre 22, 2019), que aparece en los comentarios de la gráfica 2, utiliza cifras referentes a la expulsión de venezolanos. Para reafirmar su argumento, aunque miembros de la Agencia de la ONU para los Refugiados (ACNUR) han señalado que este tipo de información se reproduce sin fundamento y no está sustentada en bases sólidas que permitan relacionar la criminalidad del país con estas personas; de hecho, en cifras generales emitidas por Migración Colombia, se estiman que en el país se encuentran 1488373 de venezolanos, de los 
cuales solo se han expulsado 1100, es decir, el 0,07 \% (Semana, 2019, noviembre 30). A pesar de todo, la percepción de inseguridad fomentada en la redes sociales apunta a encontrar el foco de riesgo en esta población.

Gráfica 2. Comentarios de la usuaria M.
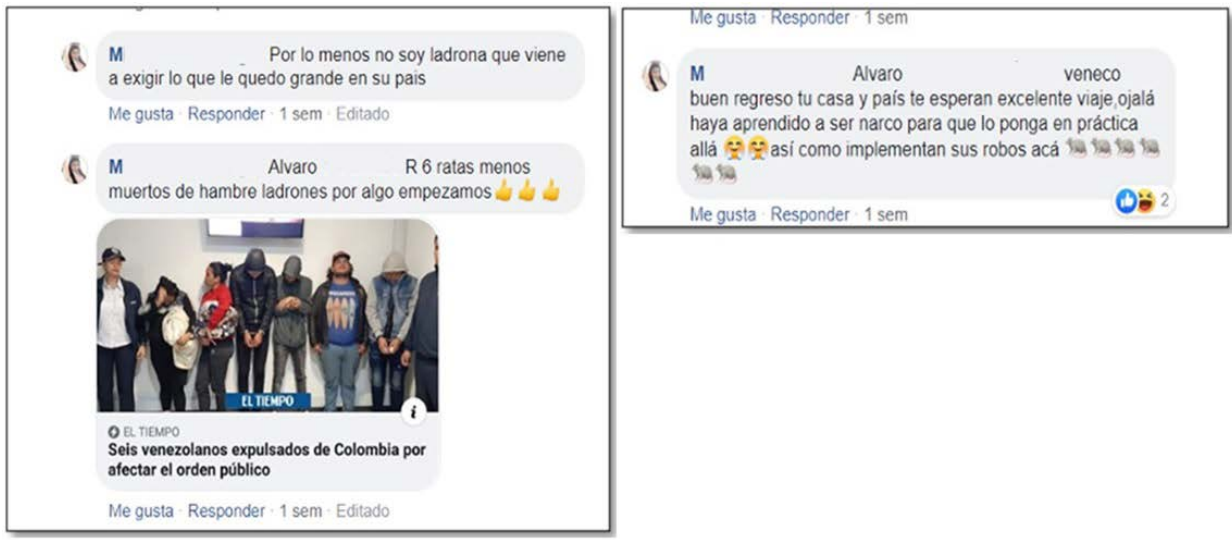

Fuente: captura de pantalla del grupo público de Facebook Arriendos Bogotá.

Aquella noche de conmoción el Estado colombiano demostró que no podía responder por la seguridad plena de sus ciudadanos, lo cual concluyó en la domesticación del peligro de inseguridad. El binomio discordante libertad-inseguridad son los pilares de un Estado neoliberal como el colombiano, el cual asegura de manera mínima la seguridad y extiende al máximo la precarización, manteniéndola en el límite de lo que se puede soportar. En este sentido, la precarización no es extrema. El Estado de inseguridad, por ejemplo, no permite que se genere pobreza absoluta, sino una capaz normalizar.

La soberanía se erige también como instrumento para gobernar y gobernarse frente a otro, y un sí mismo precarizado por las normas que promulgan la idea de ciudadanos soberanos. Se convierte en garantía de seguridad a la que pueden acceder aquellos que se sometan y que se sienten permanentemente amenazados junto con sus propiedades. Soberanía y precariedad fundadas como prácticas de autogobierno son el escenario donde los sujetos ponderan su aislamiento y las relaciones que constituyen consigo mismos, más que con los demás. Empero, esto no es independencia, aunque pueda ostentar dicha apariencia. Existe, principalmente, voluntad del sujeto más allá de la coerción; sin embargo, esta es una de las posibilidades que se 
pueden dar en el gobierno de los precarios porque también están en el otro extremo: aquellos que no quieren someterse, ser serviles, ni gobernadosgobernarse de esta manera (Lorey, 2016).

La situación de inseguridad que se vivió aquellos días generó una histeria colectiva que se agudizó y esparció como un virus de contagio inmediato cuando hubo exposición y contacto con videos, fotos y audios que circulaban por las redes. Es así como «el deseo de seguridad individual se mantiene de forma específica mediante la ansiedad generada por verse expuesto a la vulnerabilidad existencial» (Lorey, 2016, p. 96). Las personas no temían por las cosas como tal, sino por la condición precaria a la que sus vidas se enfrentaban. Frente a esto aclamaban por la intervención de la fuerza pública, es decir, suplicaban la protección del Estado (Lorey, 2016).

\section{Marcos visuales de guerra}

El giro ocasionado por las manifestaciones dejó entrever que hacer la guerra en pleno siglo XXI va más allá de los enfrentamientos armados. A partir de la idea de marcos, Butler (2010) articula la relación de la guerra

[116] con las culturas visuales, de este modo replantea la materialidad de la guerra, la cual organiza la experiencia para reconocer unas vidas como aprehensibles, pensables, necesarias, reales y otras que no. El marco desde esta posición es un control visual y narrativo que implica la regulación de la comprensión de la violencia, no solo en un sentido físico, sino como penetración y fabricación de un enemigo. Los marcos visuales de guerra encuadran determinado contenido. Son una estrategia de contención, en tanto produce y hace cumplir de un modo selectivo aquello que contará como realidad, aunque no siempre pueda abarcar lo que trata de hacer visible y legible; intenta excluir e instrumentalizar otras versiones de interpretación de algún asunto.

Enmarcar la guerra desde lo visual conlleva la producción del campo sensorial: el sonido con la imagen son piedras angulares para la fabricación de una realidad que justifique el apoyo y el consenso sobre la guerra, lo cual evita la organización de revueltas en contra. La guerra se genera sobre y desde los sentidos, sin la alteración de estos no se podría llevar a cabo. Desde este punto de vista, la cámara y la reproducción de su contenido son un instrumento para hacer la guerra, convierte a las personas en objetos visuales útiles y desechables al mismo tiempo. Una guerra implica legitimar 
la privación de la vida de las poblaciones que se encuadran como objetivos, de este modo se les atribuye el estatus de objeto y se extrae su humanidad; a su vez, dentro del mismo contexto, se precisa qué vidas deben ser conservadas y cuáles no. Con estas marcas no solo se produce, sino que se reproduce la precariedad de los cuerpos, en tanto clasifica unos que merecen ser llorados y otros que no, sosteniéndolos en el límite de la muerte. En los comentarios presentados anteriormente se destaca ese desprecio hacia la corporalidad de las personas venezolanas.

En general, todos los cuerpos son precarios y vulnerables, debido a la finitud misma de la vida y a la necesidad de cuidados; no obstante, algunos están más sujetos a la precaridad que otros, es decir, adolecen de los mínimos de asistencia económica y social, razón por la cual están más expuestos al daño, la violencia y la muerte, es una condición políticamente inducida (Butler, 2010, p. 46). El cuerpo se sostiene a través de las relaciones sociales: si ese otro no me reconoce como humano entra a tambalear la posibilidad de poder vivir una vida digna, lo cual revela una condición precaria. En este sentido, el cuerpo tiene una condición pública atravesada por un marco de inteligibilidad que reconoce unos cuerpos y otros no. Si bien este marco es dinámico, organiza y decide qué vidas son legibles y cuáles no.

La reproducción y circulación de piezas audiovisuales durante el 21 y 22 de noviembre de 2019 trajeron consigo una ola de comentarios indiscriminados que con el paso de las horas se hacían más agresivos. Estos fueron el mecanismo por medio del cual los migrantes venezolanos se produjeron como objetos visuales útiles y desechables al mismo tiempo, se configuraron como un enemigo al que se debía repudiar y atacar. Es así como los marcos por medio de los cuales se concibe la guerra definen no solo aquel-aquello que se excluye, sino también marca «los límites de lo pensable»(Butler, 2010, p. 24); es decir, cuándo una vida se puede considerar como pensable o impensable de ser vivida. Definir estas fronteras ocasiona que hacer la guerra y eliminar a los impensables resulte más fácil porque no son merecedores de duelo. De esta manera estas muertes no se consideran como violentas, sino justificables.

La responsabilidad de los supuestos hurtos y saqueos que se depositó en los migrantes del vecino país tomó mayor impulso con la noticia de la expulsión de 61 venezolanos por actos «vandálicos» durante las manifestaciones del 21 y 22 de noviembre (Trucco, 2019, noviembre 25; Aguilar, 2019, noviembre 
25). Los comentarios de las redes también estallaron, acusaban a ese otro exterior - no nacional- de los desmanes. A pesar de que las autoridades en cabeza del entonces alcalde de Bogotá, Enrique Peñaloza, declararon ante los medios que estas acciones no fueron reales y que eran parte de una campaña para difundir pánico en la ciudad, la rabia y xenofobia se extendían en los comentarios de Internet.

La producción y clasificación de los cuerpos en amenazados o amenazadores propicia relaciones jerárquicas naturalizadas desde un aspecto político y social, lo cual conlleva a la determinación y señalamiento de un cuerpo que se produce como amenaza para hacer visible de qué o de quién se deben cuidar, cuestiones que ubican unos marcos donde unos cuerpos son legítimos a costa de esos otros considerados como peligrosos. La condición precaria se traslada a los cuerpos, se extiende a estos lo inseguro, lo imprevisible y lo contingente a través de los ensamblajes de lo precario y la articulación de elementos funcionales, así se relacionan en el mismo ámbito y son necesarios para que el sujeto busque protección e inmunización contra dos duplas: inseguridad-vulnerabilidad e incertidumbre-amenaza (Lorey, 2016).

[118] Por ende, la materialidad de la guerra por medios visuales se establece cuando se identifica un cuerpo cuya vida no se considera igual de valiosa (Butler, 2010). Estos son los márgenes en los que operan los actos performativos bélicos; asimismo, se crean jerarquías entre los que están y los que no, de los legibles e ilegibles culturalmente. No pertenecer significa no tener, no tener ni siquiera cuerpo, pero estar sometido a la sanción y violencia social que produce el miedo y repudio de ese "otro» para que no sea lugar de deseo; por esta razón, se le patologiza, se excluye de la protección legal del Estado, de otras esferas, y la vida comienza a tornarse invivible. Estos son los abyectos: cuerpos monstruosos que generan una amenaza.

En el caso del grupo público de Facebook Arriendos Bogotá, algunos usuarios identifican estos cuerpos ilegibles como ese exceso que debe ser eliminado, cuya existencia no solo pone en riesgo y en peligro a los demás, sino que se hace desagradable. A estas personas se les denomina despectivamente «venecos». Aunque el término se viene reproduciendo desde hace mucho tiempo, aquel día de conmoción este se empleó de la manera más ofensiva, hasta el punto de amenazar la vida de las personas. 
Gráfica 3. Comentarios de los usuarios $\mathrm{R}, \mathrm{N}$ y J.
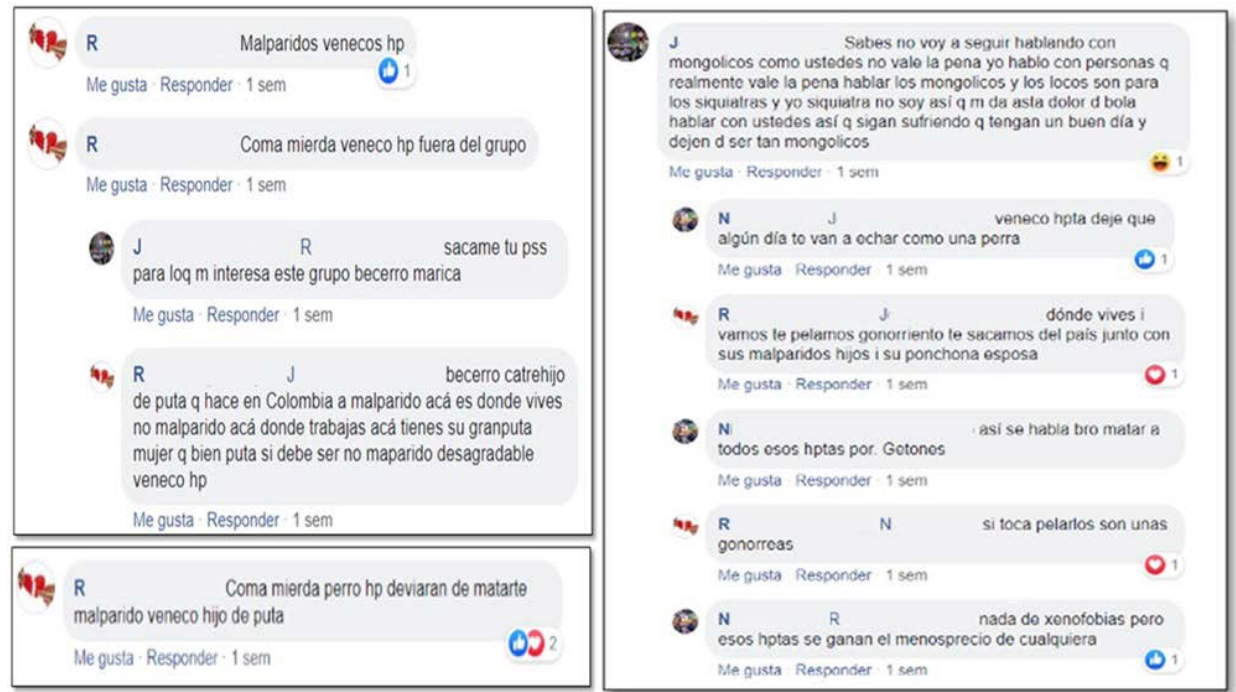

Fuente: captura de pantalla del grupo público de Facebook Arriendos Bogotá.

Estas opiniones permiten observar cómo opera la performatividad del discurso referente al enemigo público. La reiteración de todo aquello que circuló por las redes sociales desplegó una cadena de citas xenófobas contra determinados cuerpos: los encarnados por las personas procedentes de Venezuela, a las cuales se les identifica como descompuestos, putrefactos, peligrosos; además, descritos como ratas, muertos de hambre, plaga y ladrones. Los actos performativos habilitan o inhabilitan acciones, de este modo, ejercen su poder vinculante por medio del Ilamado que genera la acción. En este caso, contienen el señalamiento de unas personas como indeseables que vienen a «usurpar lo poco que le queda a Colombia» y que «vienen a exigir lo que le quedó grande en su país» (véase gráfica 2).

Los comentarios en la gráfica 4 se originan a partir de un video en el que aparecen unas personas aparentemente saqueando el supermercado Surtimax en el barrio Patio Bonito, al suroccidente de Bogotá. La usuaria M es quien publica el video en el que responsabiliza a los migrantes de los presuntos hurtos. 
Gráfica 4. Comentarios de los usuarios M, G, A, Y.
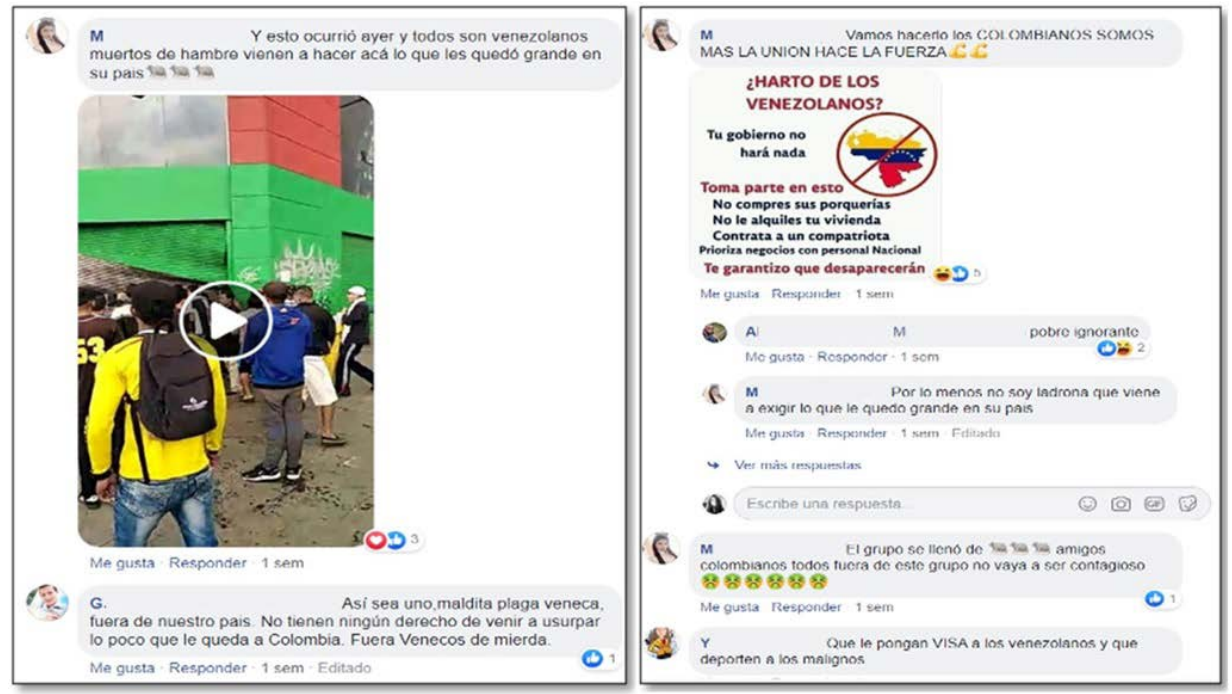

Fuente: captura de pantalla del grupo público de Facebook Arriendos Bogotá.

En los comentarios de la usuaria $\mathrm{M}$ se reproduce un discurso asociado

[120 ] con la nacionalidad, además de señalar que el grupo se ha llenado de ratas -en referencia a los venezolanos-, Ilama a los «amigos colombianos» a salir del página de Facebook apelando a la idea del contagio. La nacionalidad es un elemento constitutivo de relaciones sociales basadas en la diferencia entre unos y otros según el lugar de procedencia, es decir, esta ficción es una de las formas que puede adquirir las relaciones de poder que señalan a unos como abyectos. En este sentido, el poder no es una realidad aplastante y unidireccional en la que las capas más altas se paran sobre las bases que son la mayoría.

El poder se maneja por medio de los discursos donde participan aquellos que defienden los términos y quienes los emplean, es decir, que se ejerce por medio de una red discursiva y de prácticas sociales. A pesar de operar por medio de aparatos e instituciones, es ejercido por todos, inmersos en una red de relaciones por las cuales circulan. Los subordinados participan de manera activa cuando consienten su posición, sin embargo, no solo son agenciados por su propia dominación, sino también ejercen resistencia por medio de contra discursos. En la situacion analizada, la circulación de noticias 
declararon la falsedad de varios videos; además, algunas personas en los comentarios analizados, como el usuario J (veáse gráfica 3), manifiestan su descontento frente a las acusaciones que otras personas estaban declarando y emplea adjetivos peyorativos, tales como «mongólicos» o «locos», para referirse a aquellos que señalaban a los nacionales venezolanos.

La subversión es entonces una práctica política donde el poder no solo tiene una facultad negativa y prohibitiva, sino que engendra una dimensión positiva y generativa que tiende a ser olvidada. El poder puede solidificarse, pero también romper con lo cristalizado, no está establecido de manera previa ni permanece inmutable. Los actores pueden identificar los intersticios para subvertirlo. A pesar de que el poder tiende a reacomodarse para absorver y neutralizar la resistencia, ese mismo proceso le implica unos desplazamientos que producen grietas, espacios, intersticios por medio de los cuales se pueden generar o no resquebrajamientos. Esto se evidenció también en los días de noviembre de 2019, a los días, semanas y hasta el año siguiente se revelaba la falsedad de los robos y los supuestos saqueos. Un año después se confirmó que varios de los hechos nunca existieron: no hubo un solo judicializado por estos sucesos y tampoco detenidos acusados de vandalismo durante la noche del toque de queda, lo único claro fueron las incosistencias entre las versiones oficiales (Caballero, 2020, agosto 24).

Reproducir a un migrante venezolano como el enemigo interno del país permite comprender los marcos visuales de guerra como múltiples y dinámicos, estos pueden variar, se modifican al igual que su encuadre, funcionan a partir de la reiteración, esto quiere decir que la materialidad nunca se da de manera completa, lo que genera fisuras, por lo tanto, su inestabilidad y la posibilidad de la rematerialización (Butler, 2002, p. 18). Por su parte, los marcos «solo pueden circular en virtud de una reproducibilidad, y esta misma reproducibilidad introduce un riesgo estructural para la identidad del marco como tal» (Butler, 2011, p. 44), lo que pone en entredicho su validez, aunque esto no implica que de manera determinista se vaya a romper $y$ a dejar de producir los efectos que nombran. Esta extraña ruptura con el contexto hace que el marco cada vez que se reproduce se rompa. A pesar de intentar reorganizarse no puede contener todo lo que quiere transmitir, contener, determinar y demás.

En la época digital, la reproducibilidad del marco visual de la guerra no se puede controlar por completo, lo cual abre la posibilidad de 
rearticulación y puede crear, incluso, los efectos contrarios que se tenían establecidos con su origen. Al estar la imagen expuesta y su circulación incontrolada se pueden generar otros modos de exhibición que pueden hacer frágiles los motivos de la guerra: socavar la capacidad de centrarse en los efectos de esta, hasta naturalizarla estableciendo sus efectos (Butler, 2011, p. 17). En esta vulnerabilidad y, en sí misma, su inteligibilidad, radica la posibilidad de fisurarse, de abrir campo a la posibilidad de subversión o instrumentalización, «lo que se da por supuesto en un caso se tematiza críticamente, o incluso incrédulamente en otro» (Butler, 2010, p. 26).

La posibilidad de desestabilizar el marco consiste en la interpretación de framer framed -enmarcar el marco- (Butler, 2010), esto es, que se ponga en tela de juicio, desenmascarar que nunca incluyó el escenario que pretendía contener, de este modo, realizar un desplazamiento crítico que perturba al marco a partir de aquello que excede este enmarque de los contextos, donde lo de afuera suple y es constitutivo de lo que está adentro y que no está completo; sin embargo, esto no fue lo que ocurrió con la hipercirculación de los videos correspondientes a falsos robos y saqueos. En este caso, logró lo que se pretendía: convencer al espectador de que había un monstruo que lo amenazaba a él y a sus propiedades, en este sentido, la cámara logró construir y destruir al enemigo fabricado. Durante esos días se puso en peligro la vida y la dignidad de miles de extranjeros, el rebote de esa información produjo los cuerpos de los migrantes como ilegibles y aborrecibles. En el grupo público de Facebook Arriendos Bogotá ahora aparecen notas aclaratorias en los enunciados: NO SE ARRIENDA A VENEZOLANOS.

\section{Conclusiones}

Los acontecimientos del 21 y 22 de noviembre de 2019 son una muestra para argumentar que vivimos en un estado de inseguridad. Estos hechos dejan un mal sabor porque aún hoy, casi dos años después, no se sabe con claridad qué sucedió. Conexión Capital (2020, agosto 19) referencia la investigación del concejal Diego Cancino en la que demuestra que durante la madrugada del 22 y 23 de noviembre 2019 no existió ninguna persona señalada ni judicializada por algún delito contra la propiedad, y solo existen siete personas capturadas por hurto contra personas, cifras muy bajas para lo que irradiaba la histeria colectiva de aquellas noches. 
Las opiniones de algunos usuarios de Facebook evidencian que la condición de inseguridad no es igual para todos, las diferencias entre unos y otros se mantienen y soportan el neoliberalismo. En este caso, contuvieron el efecto ficcional de la nacionalidad para encuadrar las vidas de los migrantes como peligrosas para la seguridad de los nacionales colombianos. En el marco actual, la gubernamentalidad se transforma, la inseguridad no sólo amenaza a los que están en el borde como las mujeres, los pobres y extranjeros, sino que, esta división se está disolviendo; entre el borde y lo interno, entre lo normal y lo precario, lo externo ya no amenaza el centro, este mismo es ahora inseguro y amenazador. La precarización no se elimina con la integración de los marginados y la solución de sus condiciones económicas y políticas, porque justamente el quo del asunto está en la normalización de la precarización y el regreso de la inseguridad social como forma de gobierno en todas las capas sociales no sólo en las zonas marginadas.

En el neoliberalismo el orden social no está en peligro a causa de la precariedad, sino todo lo contrario, a través de ese otro precario, que opera la precarización como gubernamentalidad, el Estado puede afianzar su discurso de otorgar seguridad a través de instituciones armadas estatales, no tanto de las instituciones de aseguramiento como hacía el Estado social, toda vez que en las condiciones presentes «cuando más se reduce el aseguramiento social, más aumenta la precarización y mayor es la batalla para elevar el máximo la seguridad interior» (Lorey, 2016, p. 74). El que no está adentro, el extranjero, debe demostrar que merece algo, al menos un mínimo de protección estatal para no ser señalados como un riesgo para la seguridad.

La precarización como gubernamentalidad va más allá de las condiciones laborales, incluye la vida de las personas y los modos de subjetivación que están constantemente tensionados entre sumisión y empoderamiento, comprende más que la parte represiva del Estado, se perfecciona en el autogobierno. No se trata de eliminar esta condición a través de la integración de los marginales o de los que se encuentran en el borde, sino de encontrar las fisuras para fortalecer la resistencia, para esto la precariedad debe dejar de ser percibida como una amenaza que conlleva a la carencia, la constricción y el miedo, porque verla de esta manera centrará las luchas en la mera exigencia de una «política de desprecarización». Esta victimización impide ver la capacidad de agencia que tiene el sujeto. La 
precariedad no es una condición establecida, todo lo contrario, con cada nuevo sistema de explotación masiva también surge un nuevo mecanismo de subjetivación que se le opone.

Lo precario deber ser entendido glabalmente, aunado a la multiplicidad de experiencias subjetivas. Solo reconociendo nuestra actual condición precaria será posible conocer y construir posibilidades de lucha que cuestionen las lógicas sociales, políticas y hegemónicas de los Estados. De este modo, podrán practicarse nuevas formas de protección, amparo y de acción política que no estén inscritas en la representación de un colectivo, sino en su mismo colapso. La precarización no está dada, está en disputa, pero no todos tienen las mismas luchas, es por esta razón que muchas corporalidades ya no pueden ser representadas por un colectivo o sindicato como en el Estado liberal. A pesar de la multiplicidad identitaria, es necesario encontrar prácticas de organización que rompan con las maneras modernas de individualización, sin dejar de lado los vínculos y relaciones entre individuos, esto es, nuevas formas de autonomía a partir de un estar con el otro.

\section{Referencias bibliográficas}

1. Aguilar, Diego. (2019, noviembre 25). Expulsan a 61 ciudadanos venezolanos que participaron en vandalismo y saqueos en Bogotá. W Radio. https://www.wradio. com.co/noticias/bogota/expulsan-a-61-ciudadanos-venezolanos-que-participaron-envandalismo-y-saqueos-en-bogota/20191125/nota/3983051.aspx

2. Arriendos Bogotá. (s. f.). [Grupo público de Facebook] https://web.facebook. com/groups/194765691010377

3. Burbano, Luis. (22 de noviembre de 2019). Venezolanos saquean surtimax de patio bonito [Vídeo]. Youtube. https://www.youtube.com/watch? $v=X U j-e S q s \_F 4$

4. Butler, Judith. (2002). Cuerpos que importan. Sobre los límites materiales y discursivos del «sexo». Buenos Aires: Paidós.

5. Butler, Judith. (2010). Marcos de Guerra. Las vidas Iloradas. Barcelona, Buenos Aires y México, D F.: Paidós.

6. Butler, Judith. (2011). Violencia de Estado, guerra, resistencia. Por una nueva política de la izquierda. Buenos Aires: Katz.

7. Caballero, César. (2020, agosto 24). Persiguiendo fantasmas: el toque de queda de noviembre. Razón Pública. https://razonpublica.com/persiguiendo-fantasmastoque-queda-noviembre/

8. Conexión Capital. (2020, agosto 19). No existió vandalismo el 22 de noviembre de 2019: Diego Cancino. https://conexioncapital.co/no-existio-vandalismo-el-22-denoviembre-de-2019-diego-cancino/ 
9. Foucault, Michel. (2014). Del gobierno de los vivos. Curso en el Collége de France (1979-1980). Buenos Aires: Fondo de Cultura Económica.

10. Gandini, Luciana; Lozano Ascencio, Fernando y Prieto, Victoria (coords.). (2019). Crisis y migración de población venezolana: entre la desprotección y la seguridad jurídica en Latinoamérica. México, D. F.: Universidad Nacional Autónoma de México.

11. Hine, Christine. (2004). Etnografía virtual. Barcelona: UOC.

12. Lorey, Isabell. (2016). Estado de inseguridad. Gobernar la precariedad. Madrid: Traficantes de Sueños.

13. Migración Colombia. (2021, enero 29). Colombia termina el 2020 con un $2.35 \%$ menos de migrantes venezolanos en su territorio. https://www. migracioncolombia.gov.co/noticias/colombia-termina-el-2020-con-un-2-35-menosde-migrantes-venezolanos-en-su-territorio

14. Rozo Galán, Karen. (2019, octubre 11). ¿Se pasaron o los infiltraron? Vandalismo en la marcha estudiantil. Caracol Radio. https://caracol.com.co/ radio/2019/10/11/tendencias/1570804336_345122.html

15. Semana. (2019, noviembre 30). ¡Ojo con la xenofobia! https://www.semana. com/nacion/articulo/xenofobia-en-contra-de-los-venezolanos-esta-disparada-encolombia/642695

16. Taraciuk Broner, Tamara. (2018, septiembre 5). Los caminantes venezolanos. Huir a pie de un país en ruinas. Human Rights Watch. https://www.hrw.org/es/ news/2018/09/05/los-caminantes-venezolanos

17. Trucco, Florencia. (2019, noviembre 25). CNN. https://cnnespanol.cnn. com/2019/11/25/colombia-expulsa-a-61-extranjeros-por-afectar-el-orden-publico-enmedio-de-manifestaciones-contra-el-gobierno-de-duque/ 